\title{
The Gas-Phase Photophysics of Eosin Y and its
}

\section{Maleimide Conjugate.}

Steve Daly, ${ }^{a}$ Alexander Kulesza, ${ }^{a}$ Geoffrey Knight,${ }^{a}$ Luke MacAleese, ${ }^{a}$ Rodolphe Antoine ${ }^{a}$ and Philippe Dugourd ${ }^{a}$.

a. Institut Lumière Matière, Université Lyon 1 - CNRS, Université de Lyon, 69622 Villeurbanne Cedex, France.

Table S1. Details of the relevant TDDFT results (c.f. Figure 4).

\begin{tabular}{|c|c|c|c|}
\hline Excited State & KS-Orbital Excitation & $\begin{array}{l}\text { TDDFT } \\
\text { Coefficient } \\
\mathrm{X}_{\mathrm{ia}}\end{array}$ & $\begin{array}{l}\text { Spacial Overlap } \\
O_{i a}=<\left|\varphi_{\mathrm{i}}\right||| \varphi_{\mathrm{a}} \mid>\end{array}$ \\
\hline \multicolumn{4}{|l|}{$[\mathrm{EY}-2 \mathrm{H}]^{2-}$} \\
\hline $\mathrm{S}_{1}(3.1 \mathrm{eV}, \mathrm{f}=0.8)$ & $\mathrm{HOMO} \rightarrow$ LUMO & 0.7 & $0.64\left(\pi-\pi^{*}\right)$ \\
\hline \multicolumn{4}{|l|}{$[\mathrm{EYM}-2 \mathrm{H}]^{2-}$} \\
\hline $\mathrm{S}_{1}(2.3 \mathrm{eV}, \mathrm{f}=0.0)$ & $\mathrm{HOMO} \rightarrow \mathrm{LUMO}$ & 0.7 & $0.004(\mathrm{CT})$ \\
\hline $\mathrm{S}_{3}(3.1 \mathrm{eV}, \mathrm{f}=0.3)$ & $\begin{array}{l}\mathrm{HOMO}-3 \rightarrow \text { LUMO } \\
\mathrm{HOMO} \rightarrow \text { LUMO+1 }\end{array}$ & $\begin{array}{l}0.49 \\
0.42\end{array}$ & $\begin{array}{l}0.025(\mathrm{CT}) \\
0.64\left(\pi-\pi^{*}\right)\end{array}$ \\
\hline
\end{tabular}




\begin{tabular}{|l|l|l|l|}
\hline$[\mathrm{EYM}+\mathrm{CA}-2 \mathrm{H}]^{2-}$ \\
\hline $\mathrm{S}_{1}(3.1 \mathrm{eV}, \mathrm{f}=0.8)$ & HOMO $\rightarrow$ LUMO+1 & 0.7 & $0.65\left(\pi-\pi^{*}\right)$ \\
\hline $\mathrm{S}_{4}(4.07 \mathrm{eV}, \mathrm{f}=0.0)$ & HOMO $\rightarrow$ LUMO & 0.7 & $0.066(\mathrm{CT})$ \\
& & & \\
\hline
\end{tabular}




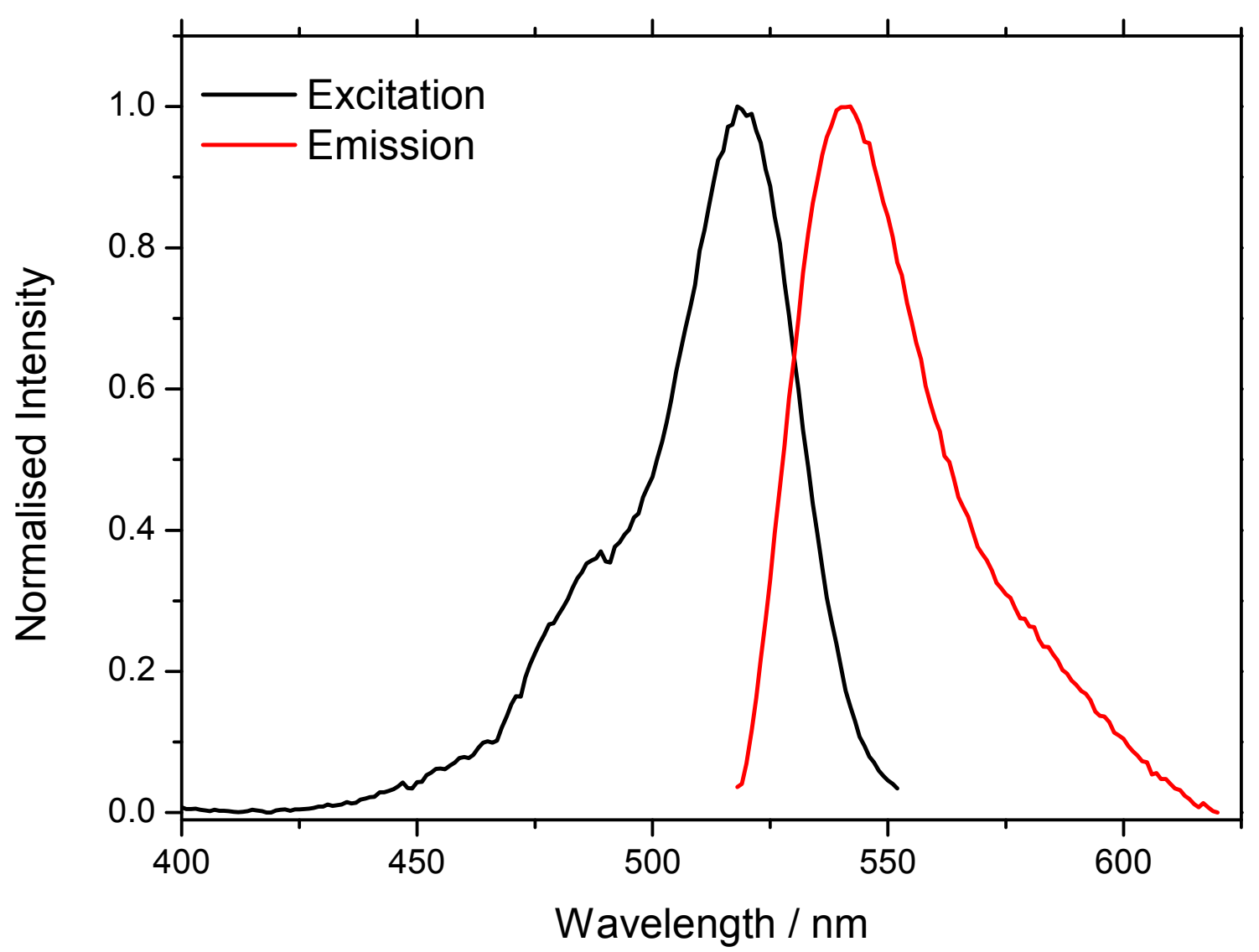

Figure S1. Fluorescence excitation (black) and emission (red) spectra of Eosin $\mathrm{Y}$ in $\mathrm{H}_{2} \mathrm{O}$ at pH 2.53. 


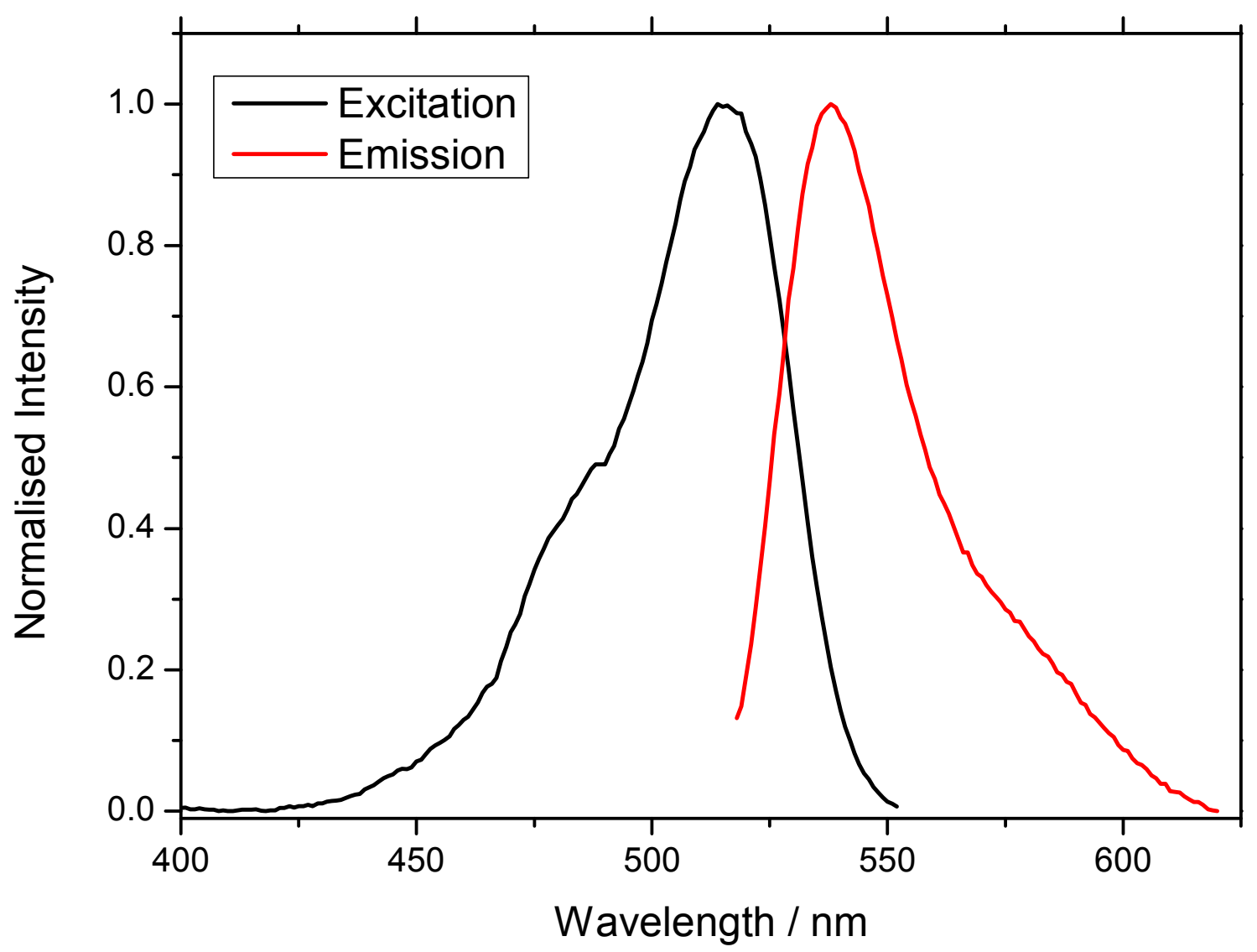

Figure S2. Fluorescence excitation (black) and emission (red) spectra of Eosin $\mathrm{Y}$ in $\mathrm{H}_{2} \mathrm{O}$ at pH 11.87. 


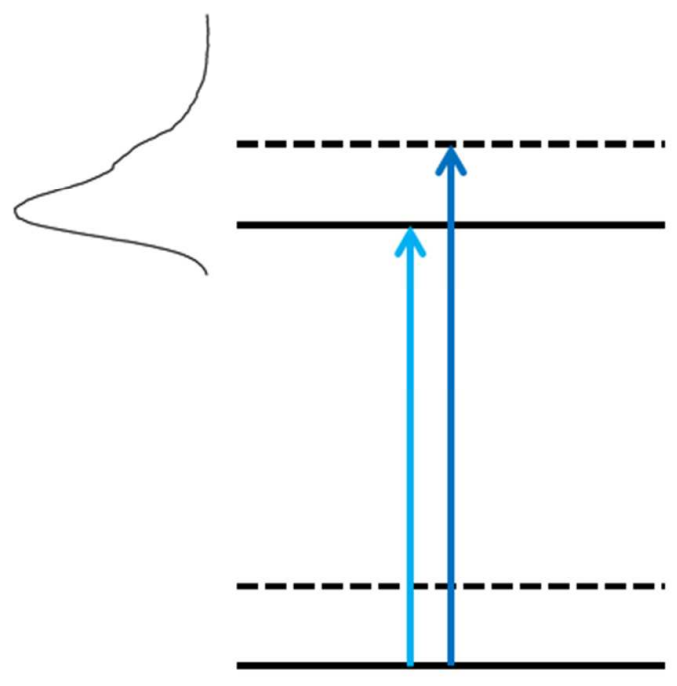

Absorption

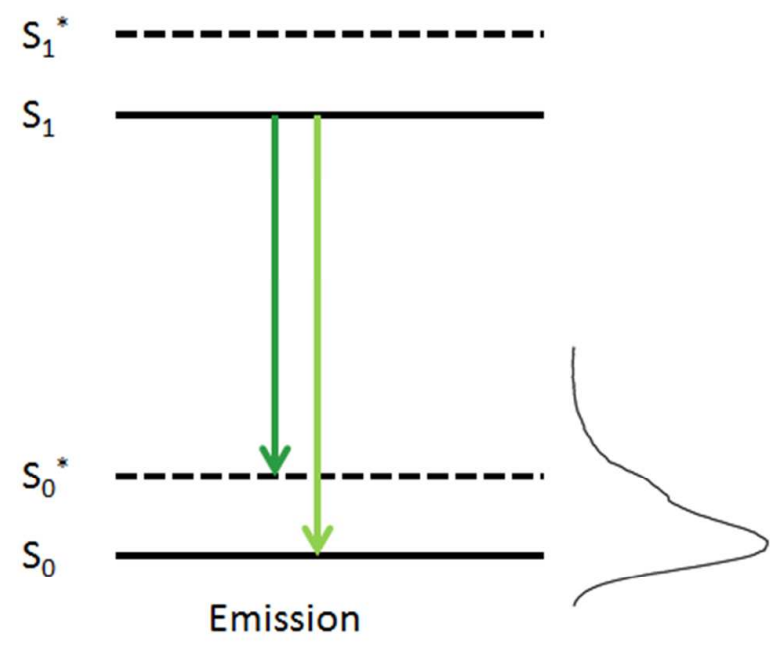

Figure S3. Schematic diagram of the absorption and emission processes leading to the observation of a shoulder in both the absorption and fluorescence spectrum of Eosin $\mathrm{Y}$. Here, $\mathrm{S}_{0}$ and $\mathrm{S}_{1}$ refer to the ground and first excited state of the system, and $\mathrm{S}_{0}{ }^{*}$ and $\mathrm{S}_{1}{ }^{*}$ refer to a vibrational level within the ground and first excited state respectively. 
Table S2. Fitted values for the fluorescence excitation and emission spectra of Eosin $\mathrm{Y}_{\text {in }} \mathrm{H}_{2} \mathrm{O}$ at different values of the $\mathrm{pH}$.

\begin{tabular}{|l|l|l|}
\hline $\mathrm{pH}$ & Excitation (shoulder) / nm & Emission (shoulder) / nm \\
\hline 2.53 & $520(492)$ & $541(567)$ \\
\hline 11.87 & $517(492)$ & $538(362)$ \\
\hline
\end{tabular}

